\title{
SPINAL ANGIOMA WITH SYMPTOMS IN PREGNANCY
}

\author{
BY
}

\author{
M. J. D. NEWMAN
}

From the Neurological Department, Manchester Royal Infirmary

Spinal cord lesions of various types may produce symptoms during pregnancy. The most common cause is disseminated sclerosis, in which the association with pregnancy of both first attacks and recurrences is well known. However, recent authors (McAlpine, Compston, and Lumsden, 1955) hold that the frequency and character of this association are not incompatible with a purely fortuitous relationship between the two conditions. A much closer association of spinal cord symptoms with pregnancy may occur in angiomas affecting the cord, and it seems probable that, in some cases at least, there is a causal connexion. Three such cases are reported here.

\section{Case Reports}

Case 1 (Hosp. No. 137802) was 24 years old when first seen in the Department of Neurology at the Manchester Royal Infirmary and was then 39 weeks pregnant. Five weeks previously she had felt sensations like electric shocks down the back of her legs to the ankles, often brought on by coughing; the following week she became unsteady and later the legs became cold and numb. On examination she was pregnant and obese. There was a spastic paraparesis with increased tendon reflexes in the legs and extensor plantar responses. Sensory loss mainly to pin prick and vibration extended up to the seventh thoracic dermatome with some sacral sparing. Radiographs taken at this time showed only minor disc changes between the sixth and seventh thoracic vertebrae. Queckenstedt's test showed a partial block of the cerebrospinal fluid and the protein level was slightly raised at $60 \mathrm{mg}$. per $100 \mathrm{ml}$. Labour was induced and within a week after delivery the paraesthesiae disappeared; a month later all the abnormal signs had regressed. Three years later she again became pregnant and remained well until about 28 weeks when she felt her legs a bit heavy. At 30 weeks she noticed numbness round the abdomen and at this time slight sensory impairment could be detected with an upper limit at the eighth thoracic segment. One week later there were signs of a pyramidal lesion, and by the 35th week the sensory level had risen to the fourth thoracic dermatome. Labour was induced and within a fortnight the symptoms and signs had regressed. At this time a more thorough radiological examination showed a typical angioma of the second thoracic vertebral body; myelography

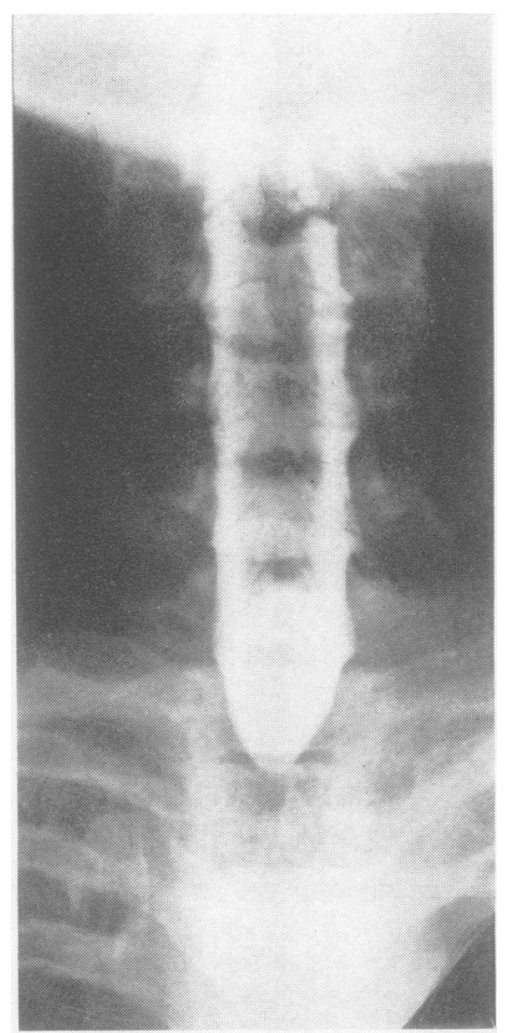

FIG. 1.-Myelogram in Case 1 to show block in subarachnoid space at the level of $D .2$ vertebra which has the appearance of an angioma.

demonstrated a subarachnoid block at this level (Fig. 1). For a year she continued to have slight tingling and unsteadiness of the legs, but when she was seen two and a half years after her last delivery there were neither symptoms nor definitely abnormal signs. After another year, however, symptoms again appeared and, having moved to London, she was referred to the Brook General N Hospital for treatment. Mr. G. B. Northcroft performed o a laminectomy on January 10,1956, and removed an $N$ extradural angiomatous mass lying mainly in front of 
the theca. She made a complete recovery and three months later was free of all signs and symptoms.

Case 2 (Hosp. No. 453/46) was aged 34. She had no symptoms until the end of her second pregnancy when she had girdle pains in the lower thoracic region; these ceased five days before delivery. She was seen in her third pregnancy, three years later in 1946. At 32 weeks the girdle pains began again, being worse when she lay down and relieved by standing; in fact she would get up and walk around when the pain came on at night. Two weeks later her legs became numb, then stiff and weak; five days before admission she became unable to walk. On examination she was 36 weeks pregnant. The legs were very weak and spastic, the abdominal reflexes were absent, knee and ankle jerks increased, and plantars extensor. There was sensory impairment, chiefly to pin prick up to the sixth thoracic dermatome. Lumbar puncture demonstrated complete spinal block, but radiographs were not technically satisfactory. Operation was decided on; the laminae of the fourth and fifth thoracic vertebrae were found to be exceedingly vascular and the extradural space occupied by a network of dilated veins. Owing to the terrifying haemorrhage nothing further was done. The paraplegia was unchanged after operation; five days later she was spontaneously delivered, but developed paralytic ileus and died. Necropsy showed a vertebral angioma and blood clot compressing the cord; no other angiomata were found.

Case 3 (Hosp. No. 272128) was a woman of 35 who, in the eighth month of her third pregnancy, developed pain in the lower back radiating down the left leg with some weakness of this leg. One month before delivery she fell and became paraplegic with retention of urine. She had a normal full-term delivery, but there was no change in her condition until four months later. Thereafter steady improvement occurred and in March, 1952, eight months after delivery, she could walk normally. But two years later there was a recurrence of pain and hesitancy of micturition and she was admitted to the Manchester Royal Infirmary in November, 1954.

On examination, she could walk with a rather spastic gait. The bladder was distended. The tendon reflexes were normal in the arms; the knee jerks were very brisk and ankle jerks absent. The abdominal reflexes were present and the plantars flexor. There was sensory impairment over the dermatomes L.5 to S.5.

A radiograph of the spine showed an angioma of the body of L.3 vertebra. No cerebrospinal fluid could be obtained by lumbar puncture, but cisternal cerebrospinal fluid contained $140 \mathrm{mg}$. of protein. Myelography showed the typical filling defects of an intradural angioma

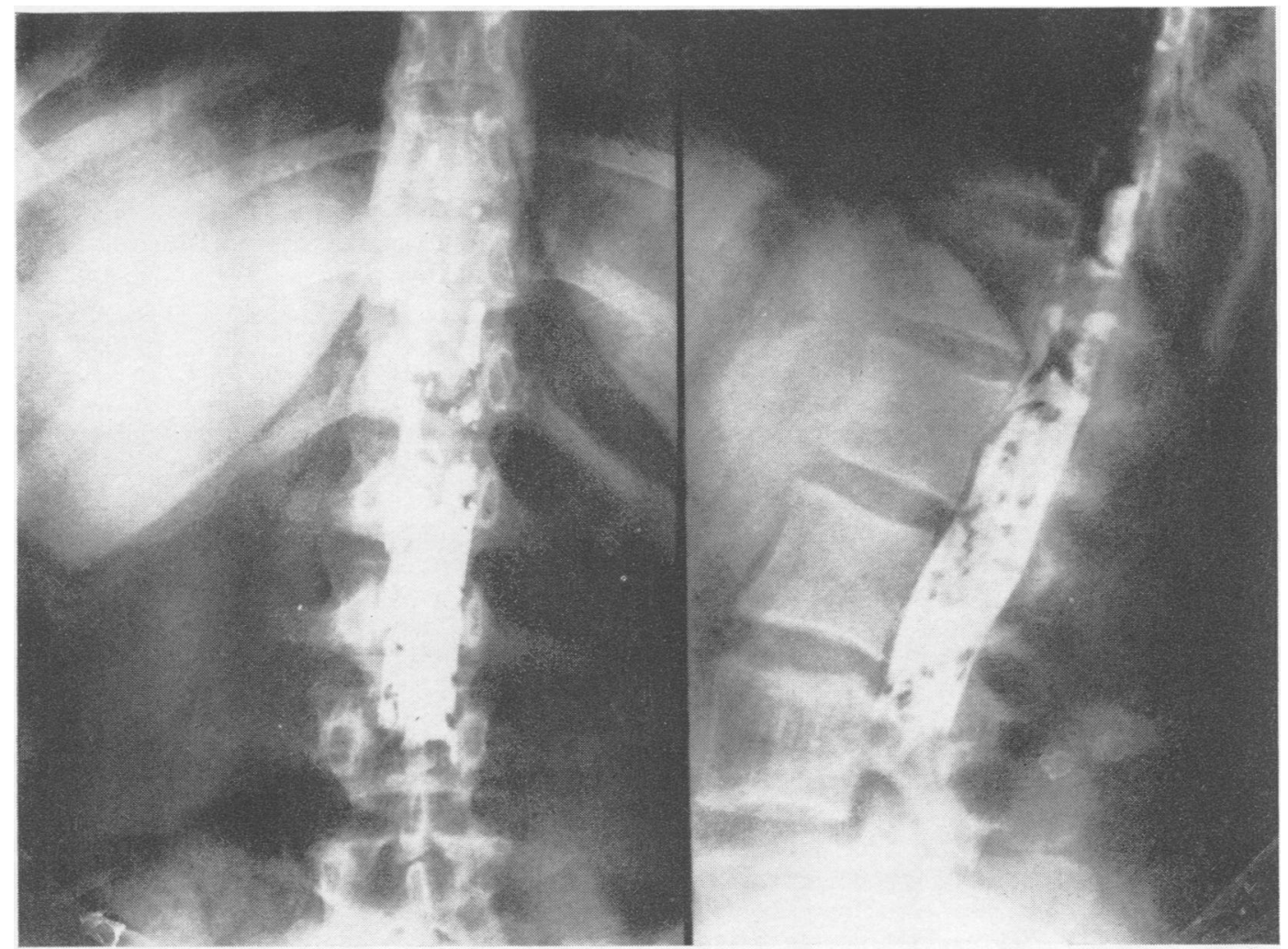

FIG. 2.-Myelogram in Case 3 to show the typical filling defects of intradural racemose angioma in addition to an angioma of the body of L.3. 
between T.11 vertebra and a complete block opposite L.3 (Fig. 2).

She was given radiotherapy and control of the bladder was regained. However, by June, 1955, walking was again worse and she had periodic retention of urine. There was now flaccid paralysis of the left leg with absent tendon reflexes, and sensory impairment was detectable up to the level of T.6.

\section{Discussion}

Balado and Morea (1928) have previously recorded, in a most striking case, similar relapses and remissions due to an extradural angioma and associated closely with pregnancy. Their patient was a woman of 36 who, in the space of 10 years developed spastic paraparesis in seven out of eight pregnancies, with complete remission between. The pattern of relapse was not the same each time; there were no symptoms at all in the sixth pregnancy, while in the seventh, paraplegia came on suddenly in the last week and continued five months after delivery, and in the last pregnancy symptoms returned at the seventh month and were fatal. At necropsy, there was found an extradural tumour in the upper thoracic region composed of interwoven large and small blood vessels and cavernous spaces.

Michon, Grégoire, and Lafont (1935) describe a patient with a vertebral angioma who developed sudden paraplegia in the last month of her sixth pregnancy. Earlier in the same pregnancy and in the two previous ones she had complained of pain in the interscapular region. Radiographs showed an angioma of the fourth thoracic vertebral body and radiotherapy three months after delivery was followed by rapid improvement. Delmas-Marsalet (1941) has reported relapse and remission in two pregnancies in a case of intradural racemose angioma. The patient was a woman of 26 who, eight years before in her first pregnancy, developed pain in the neck and arms made worse by coughing and straining and eased by standing upright. Later there was some weakness of the legs but all the symptoms disappeared "as if by miracle" on delivery. A precisely similar sequence of events occurred in the second pregnancy, but three years later the symptoms recurred and progressed although she was not pregnant. Examination showed spastic paraplegia with a sensory level at the second thoracic dermatome; myelography was typical of racemose angioma with changes extending over the upper thoracic region; laminectomy showed the expected lesion, apparently venous in nature, lying beneath the dura and attached to the cord.

Other authors have reported less striking episodes: Bergamaschi (1956) in a case of vertebral angioma, Lam, Roulhac, and Erwin (1951) in an epidural haemangioblastoma and Girard and Garde (1955) and Brion, Netsky, and Zimmerman (Case 7, 1952) in intradural angiomas.

The cause of the production of such symptoms may be supposed to be due either to a direct increase in venous pressure from the enlarging uterus or to the effect of the hormones produced in pregnancy on the walls of blood vessels. Simple obstruction might well have brought about the onset in Case 3. In the other cases the lesion was in the upper thoracic region and venous drainage from the angioma must have been mainly into the superior vena cava where increase in pelvic pressure would have little effect. In Delmas-Marsalet's case symptoms began in the second month of pregnancy before any major mechanical effects could have made themselves felt. It seems more likely that an altered hormonal environment with increased circulating oestrogen and progesterone caused dilatation of the abnormal vessels and their feeding arterioles, or possibly constriction of the draining venules. A similar explanation has been advanced for the distension of varicose veins in early pregnancy and, less plausibly, for the appearance of spider naevi in liver disease. A patient personally observed had a cutaneous angioma of cavernous type on the upper trunk which enlargedo in early pregnancy and returned to its previous size after delivery; a similar sequence of events is described by Davis (1938) while spider naevi frequently appear in pregnancy and disappear after delivery.

Epstein, Beller, and Cohen (1949, Case 1) and Pappenheim (1938, Case 1) have reported cases of intradural racemose angioma in which symptoms were aggravated at the menstrual periods, further supporting the hypothesis of a hormonal effect, and Johnson (1957) reports a similar occurrence in angiomas of the brain-stem. On the other hand, the relief of pain on standing in Case 2 points to the importance of simple hydrostatic factors.

While simple coincidence of symptoms with pregnancy must be considered in some cases, prompt improvement after delivery is very suggestive of a causal connexion in a condition such as vertebral angioma where spontaneous remission does not occur except post partum; recurrence of symptoms at the same level in successive pregnancies also indicates that the relation is unlikely to be merely a chance one.

The occurrence of a transverse spinal cord lesion during pregnancy should always raise the possibility of an angioma, most frequently one in the vertebral bodies or epidural space. Although these lesions are admittedly rare, those involving the vertebra are readily diagnosed radiographically and are amenable to radiotherapy; in most cases dramatic improvement takes place in a matter of weeks. Isolated epidural angiomas are seldom diagnosed 
except at operation but the intradural type often shows a characteristic pattern on myelography; treatment of the latter, however, is most unsatisfactory.

I am grateful to Dr. F. R. Ferguson for permission to publish these cases and to Mr. G. B. Northcroft for details of the later progress of Case 1 .

\section{REFERENCES}

Balado, M., and Morea, R. (1928). Arch. argent. Neurol., 1, 345.

Bergamaschi, P. (1956). Riv. Ostet. Ginec. prat., 38, 163.
Brion, S., Netsky, M. G., and Zimmerman, H. M. (1952). A.M.A. Arch. Neurol. Psychiat., 68, 339.

Davis, A. (1938). J. Obstet. Gynaec. Brit. Emp., 45, 667.

Delmas-Marsalet, P. (1941). Presse méd., 49, 964.

Epstein, J. A., Beller, A. J., and Cohen, I. (1949). J. Neurosurg., $6,45$.

Girard, P. F., and Garde, A. (1955), Gaz, méd. Fr., 62, 1175.

Johnson, R. T. (1957). Address to Section of Neurology, R.S.M.,

Lam, R. L., Roulhac, G. E., and Erwin, H. J. (1951). J. Neurosurg., $8,668$.

McAlpine, D., Compston, N. D., and Lumsden, C. E. (1955). Multiple Sclerosis, p. 51. Livingstone, Edinburgh.

Michon, P., Grégoire, and Lafont, J. (1935). Rev. neurol. (Paris), $63(1), 565$.

Pappenheim, E. (1938). Dtsch. Z. Nervenheilk., 146, 284.

\section{THE NOVEMBER (1957) ISSUE}

The November (1957) issue contains the following papers:-

Arteriovenous Malformations of the Brain and their Effect upon the Cerebral Vessels. Juan Carrasco-Zanini.

The Late Sequelae of Pneumococcal Meningitis. Honor V. Smith, R. M. Norman, and H. Urich.

Electro-encephalography in a Case of Islet Cell Adenoma. John Laidlaw and S. M. Rab.

Manifestations of Suprarenal Insufficiency Occurring with Pituitary Tumours. Antony Jefferson.

Neurological Manifestations in Haemangioma of the Vertebrae. H. Askenasy and A. Behmoaram.

Rapidly Progressing Dementia in Disseminated Sclerosis. J. D. Bergin.

Fatal Damage to the Brain by Epileptic Convulsions after a Trivial Injury to the Head. J. M. Small and A. L. Woolf.

Frequency Analysis of Physiological and Neurotic Tremors. J. W. T. Redfearn.

Book Reviews.

Index to Volume 20.

A number of copies are still available and may be obtained from the Publishing Manager, British Medical Association, Tavistock Square, W.C.1, price 12s. $6 d$. 